\title{
Communicative Competence: A Study of English for Tourism in Asian Region
}

\author{
Caezar D. Pamin, Ph. D. \\ caezarpamin01111983@gmail.com \\ Laguna State Polytechnic University, Santa Cruz, Laguna, Philippines
}

\begin{abstract}
The study utilized the descriptive research design. It involved one hundred twenty guests of selected tourists' attractions in Asian countries particularly from Siem Reap, Cambodia, Ho Chi Minh, Vietnam and Taipei, Taiwan who were selected using purposive sampling from whom the data needed to answer the questions: 1) What is the level of guests' interest in bilingualism? 2) What is the level of guests' second language exposure? 3) What is the mean level of oral English proficiency as to vocabulary in terms of diction, grammar with regard to syntax and subject-verb agreement and fluency in terms of pronunciation? 4) Do interest in bilingualism \& dual language exposure have a significant effect to oral English proficiency?
\end{abstract}

Only one set of questionnaires and set of interview questions were utilized as major instrument in gathering and treating the data for the two areas of investigation. To maintain the credibility of the paper the questionnaire contained five-point likert scale of alternative answers after which the responses of the respondents were tallied and treated using mean, standard deviation and ANOVA to produce the counts as basis for empirical testing of the hypothesis.

The conclusions were drawn and recommendations were endorsed from the findings made relative to above basic questions raised. Analysis of the data gathered yielded this conclusion: Interest in bilingualism and second language exposure have "significant effect" on the oral English language proficiency in terms of vocabulary, grammar and fluency.

Keywords: Bilingualism; Second Language Exposure; Vocabulary; Grammar; Fluency

\section{Introduction}

Communicative competence is the art of being engage in conversations in appropriate and informative ways and bilingualism is the ability of using two different languages. The whole world was exposed to numerous languages as they move from one place to another. Specifically, the Asian region where language diversity is very evident.

There is a number of languages spoken throughout the world. A very small number of languages such as Arabic, Bengali, English, French, Hindi, Malay, Mandarin, Portuguese, Russian and Spanish, which serve as important link languages or languages of wider communication around the world are very often spoken as second, third, fourth or later-acquired language by their speaker. Tucker (1999). Although fewer than $25 \%$ of the world's 200 countries recognize two or more official languages, available data indicate that there are monolinguals. In addition, many more children throughout the world have been, and continue to be, educated via a second or later-acquired language than the number of children educated via first language. 
In many parts of the world, bilingualism and multilingualism and innovative approaches to education that involve the use of two or more languages that constitutes the normal experiences (Dutcher 1994). Singapore is no exception since it is ranked 5th among non-native English-speaking countries globally behind Netherlands, Sweden, Norway, and Denmark. The island nation was also the only nation in Asia deemed to have very high proficiency in English. Coming in second in Asia is the Philippines, with an EPI of 60.14 (high proficiency).

Among the 36 Asian nations, the TOP 5 countries with the highest English proficiency were Singapore (No. 6), Philippines (No. 20), Malaysia (No. 26), Hong Kong (No. 32), and India (No. 33). Rounding up the top 10 were: South Korea (No. 37), Taiwan (No. 38), China (No. 40), Macau (No. 41), and Vietnam (No. 52) In other parts of Asia, the United Arab Emirates came in 17th in Asia and 70th globally. Kyrgyzstan came in 36th in Asia and 99th globally, with an EPI score of 41.51 (low proficiency). Papadopoulos (2019)

The use of more than one medium of instruction and exposure to the second language affect the communicative competence of tourists' escorts in selected Asian countries in terms of vocabulary, grammar and fluency.

English Language Proficiency is commonly defined as the person's ability to speak or perform in English with fluency (Hirsch, 2011). In order to evaluate an individual's abilities, the Test of English as Foreign Language was established by Educational Testing Service and is administered worldwide to measure the ability to employ college-level English in terms of listening, speaking, reading and writing skills.

Examination of English language proficiency in Vietnam shows that students and lecturer share generally low English proficiency. For example, a recent notable investigation from Danang University (2012), one of the most leading institution in Vietnam, shows that $70 \%$ of the newly enrolled students have insufficient English proficiency to pursue studies in English. With such level of competency students would be unable to comprehend lectures or materials in English.

Collier (2011) defines English Language Proficiency as the language that is predicted on a sociotheoretical foundation. This means that the language is more than just a sum of discrete parts such as pronunciation, grammar, and vocabulary. It is developed within the culture for the purpose of conveying vie reliefs and customs of culture.

According to Collins (2011), the language usage is dynamic and contextually based (varies depends on the situation, status of the speakers and the topic) the discursive requires connected speech, and requires the use of integrative skills to achieve communicative competence.

Marcelo in an article dated February 21, 2010 says that proficiency of our skilled workers in English is being eroded fast by rising competition from other countries and the declining mastery of English language by our college graduates.

McLean (2010) states that as the economy has under-performed, so as the education. About 43 percent of students finish high school but only 2 percent of studies finish college. 
Wallace (2007) recognizes the importance of English proficiency. According to him, English is very much needed in order to meet the demands for highly equipped graduates globally. It was also stated that being proficient in the English language is one of the keys to become globally competitive.

Balili (2007) says that a student who is competent with the use of the English language has an edge over others in terms of job opportunities.

English played a very important role in our communication. English, as an international language spoken in many parts of the world, is also one of the languages in Asian Education.

Asian learners have no choice but to use their mother tongue to preserve their cultural heritage, culture and to promote tourism. However, English has become a more important language academically and politically.

One of the factors under the Oral English Language proficiency is vocabulary which has been given numerous definitions.

Nelson (2011) gives his insights about vocabulary, "Knowing lots of words is like a key: the more words they know, the better able they'll be able to choose the right ones as they communicate."

Penn (2006) says that building vocabulary is a process that takes time. Learning new words and how to use them is not something you learn overnight. Listening and reading helps you build new vocabularies.

Mercado (2013) mentions that students acquire vocabulary knowledge as they pick up meaning of words from a context. Repeated encounters with words reinforce the odds that vocabulary growth occurs.

Knowing a word involves an understanding of the word's definition as well as word's approximate contextual usage. (Stahl and Fairbank 2006). Moreover, Graves and Penn (2006) states that researchers agreed that knowing a word is an incremental process that takes time and repeated exposure.

Miffin (2009) states that vocabulary is all the words of a language. The sum of words used, understood, or the command of a particular person or group. The stock of words used by or known to a particular person or group. A list or collection of words and often phrases usually arrange to express or communicate by tooting of by visible signs. Anything written or printed, anything expressed in characters or letters. Any legal instrument, as a deed, a receipt, a bond of agreement, or the like. Letters or symbols written or imprinted on a surface to represent the sound or words of a language.

Zamora (2008) was even more specific when she states that this process includes three primary aspects (a) the subtleties of a word's various meanings, (b) the ranges of those meanings, and (c) the suitability of the word in context.

Askari (2010) states that vocabulary knowledge is important because it involves all the words that students need to access within their stock knowledge, share their thoughts and have an effective conversation and absorb new information. 
Diction is the sub-category of vocabulary. As defined by Mason (2005), diction concerns how people choose words, especially with the correctness, clearness or effectiveness.

Another definition was given by Palmer (2007), he notes that diction has a number of attractive features that could be used to analyze unique elements of a language in spoken or written language.

The genre of the spoken and written languages greatly affects diction or the choice of words, the language in poetry is different from everyday language, Wikstrom (2007).

Diction is very crucial in translating scientific and technological articles compared to narrative or descriptive articles Zao (2009)

Badillo (2015) states that choosing the right word is probably the most difficult part of both speaking and writing. Using just the right words is at the heart of everyone's wish to be understood.

The definition provided by Merriam-Webster Dictionary (2015) grammar is the set of rules that explains how words are used in a language.

The grammar is the nuts and bolts of a language. It is a foundation stone to get the grip of a language and master it. So, a sound knowledge and clarity in comprehending English grammar is mandatory for every English language teacher. Just like the nuts and bolts needed to be used for smooth functioning of an engine, similarly sound knowledge of English grammar is a must (ESLarticle.com,2014)

Abdullah (2011), the acquisition of grammatical structures concerns the steps s person underwent. Certain grammatical structures and morphemes are required before others in the first language acquisition.

According to Nelson (2005), Language and language varieties are rule governed. Some forms are meanings. Grammatical acceptable; others meaningless; ungrammatical and unacceptable.

Tompkins and Hoskison as cited by Ebarva (2015) states that grammar is no end in itself. Rather it should be viewed as a means to achieve clarity in both oral and written languages.

Butterfield (2008) grammar is a set of structural rules that governs a composition of clause, phrases, and words in any given natural language. The terms refer to the study of such rules and this field included morphology, syntax and phonology, often complemented by phonetics, semantics and pragmatics. Linguists do not usually use the term to refer to orthographical rules, although usage of books and styles guides that call themselves grammars may refer to spelling and pronunciation.

Harner (2010) also assess, "Without the lexical knowledge they (learners) would not be able to use the grammar to generate the sentences with meaning" and "an ability to manipulate grammatical structures which does not have any potential for experiencing meaning unless words are used."

Palisin (2015) says that the study of how words and heir component parts combine to form 
sentences. The study of structural relationships in language or sometimes including punctuation, meaning and linguistic history, the system of inflection, syntax and word formation of language, viewed as a mechanism for generating all.

Syntactic component governs the hierarchical organization of words and phrases in sentence, Wilga (2019).

Okanoya (2012) notes that the domain of syntax is seen as the core of language faculty and as the most critical difference between animal vocalizations and language.

Palmer (2007) states that the syntax is a special element of language since it can affect the meaning of the spoken and written language. Brown (2008) states that a child undergoes a process to acquire syntax.

Mills (2007) aforementioned that subject-verb agreement is important for comprehension. Another definition that supports the claim of Mills was stated by Bucker (2010) as he points out that agreement is an early, integral component of comprehension.

Cutting (2011) says that errors in subject-verb agreement is very common in the spoken language. Ramsey (2007) states that there should be more testing and processing of subject-verb agreement.

Hart (2006) says that subject and verb always go together so they should always agree.

The most commonly used definition of fluency is the ability to read connected text rapidly, smoothly effortlessly and automatically with the little conscious attention and the mechanics of reading such as decoding (Asuncion,2012).

Bucker (2010) states that fluency plays an important role in developing and becoming a good reader. Good readers are fast efficient problem solvers who use meaning and syntax as they quickly and efficiently decode unfamiliar words in order to be truly fluent, a reader must comprehend and interpret text and read with appropriate timing, expressiveness, stress, and intonation.

Pronunciation being an indicator of fluency is defined as a linguistic. feature that is most commonly judge, Canagarajah (2005). Since listener can easily judge if a person mispronounces a word.

Despite the fact that acquiring pronunciation is so difficult, in many ESL/EFL classrooms, teaching pronunciation is granted the least attention, Duran (2014).

Carol (2006) concludes that pronunciation is affected by age factors, age groups considered nature of the pronunciation test and length and type of exposure to the second language.

Wei (2006) states that English pronunciation is still neglected in EFL ESL classrooms throughout the world, including Asia today. One of the reasons that it is neglected or ignored us because not many English pronunciation teaching strategies or techniques are available to teachers in the classroom.

Pronunciation has been greatly affected by how the first and the second language of a person 
is acquired.

Bilingual education can be defined as an educational program in which two languages are used to provide instruction. It is a simple label for a complex phenomenon. An important distinction is between those programs that use and promote two languages and those where bilingual children are present, but bilingualism is not fostered in the curriculum.

Skuttnab-Kangas as cited by Sobrepefia (2010) offers three broad categories that encompass the range of education programs.

Immersion programs promote additive bilingualism for majority language speakers. These are highly valued educational programs and the most well-known are the French immersion programs for English speaking children in Canada. Although teaching is provided in the second language, the teacher knows and may use both languages.

Submersion programs are programs where linguistic minorities are taught the medium of the majority language with minimal or no support to enable learners to understand the language of instruction or access the curriculum content. Often, the minority language and cultures are not highly valued by the majority group.

Maintenance programs provide teaching in the first language in order to maintain use of the home language and culture. These programs are often lied to transitional bilingual education programs where the learners gradually move towards full use of the majority language.

Most bilingual education programs have two goals: the acquisition of language of the country and academic success: and the continuing development of the heritage language, (Franson 2009).

At lowest levels of knowledge and awareness, exposure to fragments of other languages is unavoidable. Bialystok (2010) reports that no language is immune to intrusion from the barrage of words and phrases that rise out of one language and through their universal appeal deposit themselves squarely into the lexicons of another.

Charles (2007) states that interest includes aspects of emotions and actions.

Another relevant definition given by Arewart (2007) says that interest is dear to 'attitude' construct, as well as 'motives' or "intrinsic reasons", usually associated with motivation.

Fonacier (2006) states that interest is most often as something that drives positive action toward the object of interest.

PISA (2006) provides a composite definition that includes curiosity and willingness.

Gaza (2011) reveals that motivation to learn a foreign language is determined by personal characteristics such as learner's attitude.

Karahan (2007) states that interest included the idea of a 'goal' as Visconde (2006) notes that 
interests interplay between values, beliefs and perceptions.

Language exposure was referred to as the opportunity to use the language in communication, Bacuyag (2011). Another relevant definition given by Gamboa (2007); he states that language exposure is being able to 'experience' the language.

Nunn (2007) states that language exposure is the use of language in a controlled and uncontrolled setting.

Sobrepena (2010) states that language exposure refers to the unlimited chances a person can use the language to communicate. And the last definition, Butterfield (2008) says that language exposure in a certain region may have different levels..

\section{Methods}

The descriptive method of research was used in the study to find out the mean level of guests' in terms of age, gender, educational attainment, economic status; the status of attitudes towards bilingualism in terms of motivation, interest, and dual language exposure: the mean level of oral English proficiency of guests' as to vocabulary, grammar, and fluency and the effect of attitudes towards bilingualism and dual language exposure on student's oral English language proficiency.

Descriptive designs include observation, surveys and interviews, standardized tests and case studies. (Salmorin 2005). Descriptive method involves collection of data in order to test and answer the question arising in the current state of the subject of the study and problems of the researcher.

Apolinario (2009) defines descriptive research as a process of gathering, analyzing, classifying and tabulating data about prevailing conditions, practices, beliefs, process, trends, cause and effect relationship and then making adequate and accurate interpretation.

The data on the study of attitudes towards Communicative Competence: A Study of English for Tourism in Asian Region utilized questionnaire and oral interview. These revealed the responses of 120 guests'.

The study covered one hundred twenty (120) purposely selected Asians from Siem Reap, Cambodia, Ho Chi Minh City, Vietnam \& Taipei, Taiwan.

The researcher designed a questionnaire and an interview to assess the interest in bilingualism, the native's language exposure and oral English language proficiency. On the other hand, an interview was raised for the researcher to have an idea regarding the English language proficiency.

The data gathered were treated using appropriate statistical tool. The weighted mean of the scores in the test were obtained by dividing the sum of the scores by the number of respondents. The weighted mean of each statement was computed by dividing the product of the total weighted mean of points and the frequency by the total number of respondents.

Mean and Standard Deviation were used to determine the level of students' interest and bilingualism. Percentage and Frequency were used to determine the status of second language exposure and level of oral 
English proficiency as to diction, grammar in terms of syntax, and subject verb agreement, and fluency as to pronunciation.

Finally, ANOVA was implemented to determine the effect of interest in bilingualism and dual language exposure to student's oral English proficiency.

\section{Results}

Table 1 shows the mean, standard deviation and remarks regarding the guests' level of Interest in Bilingualism.

As shown in the table below, it can be gleaned that relative to Interest in Bilingualism, if guests' are not proficient in English, they "agree" to be in a conversation using English and Mother Tounge in conversation as evidenced by the mean of 4.70 and standard deviation of 1.02. If they develop literacy in mother tongue, they "agree" that it will facilitate the development of reading and writing in English with mean of 3.80 and SD od 0.86. Asians "agree" that high level of familiarity with mother tongue and English can lead to practical, career related advantages, mean $=4.10$ and $\mathrm{SD}=1.00$ and can result in higher development of knowledge or mental skills mean $=4.29$ and $\mathrm{SD}=0.90$. Likewise, the "agree" to engage in conversation where mother tongue is used and if they are with tourists, they speak English better with mean of 4.22 and 4.02 and SD of 0,93 and 1.08 respectively.

Table 1. Level of Interest in Bilingualism

\begin{tabular}{|l|l|l|l|}
\hline Question/s & Mean & SD & Remarks \\
\hline $\begin{array}{l}\text { If I am not proficient in English, I should still be in a } \\
\text { conversation using English and MT. }\end{array}$ & 4.07 & 1.02 & Agree \\
\hline $\begin{array}{l}\text { If I develop literacy in MT, it will facilitate the development } \\
\text { of reading and writing in English. }\end{array}$ & 3.80 & 0.86 & Agree \\
\hline $\begin{array}{l}\text { High level of familiarity with MT and English can lead to } \\
\text { practical, career related advantages. }\end{array}$ & 4.18 & 1.00 & Agree \\
\hline $\begin{array}{l}\text { High level of familiarity with MT and English can result in } \\
\text { higher development of knowledge or mental skills. }\end{array}$ & 4.29 & 0.90 & Strongly Agree \\
\hline $\begin{array}{l}\text { I should talk with guests where MT is part of the } \\
\text { conversation. }\end{array}$ & 4.22 & 0.93 & Strongly Agree \\
\hline $\begin{array}{l}\text { If I am in an English only conversation, I will learn English } \\
\text { better. }\end{array}$ & 4.02 & 1.08 & Agree \\
\hline I must learn English as quickly as possible. & 3.71 & 0.99 & $\begin{array}{l}\text { Mgree } \\
\text { Agree }\end{array}$ \\
\hline \begin{tabular}{l} 
I prefer English over MT as tool in conversation \\
\hline $\begin{array}{l}\text { I think the use of both languages helps understand the guests } \\
\text { better. }\end{array}$
\end{tabular} & 4.38 & Agree \\
\hline $\begin{array}{l}\text { I find it interesting when guests use both languages in } \\
\text { conversation. }\end{array}$ & 4.37 & 1.01 & Agree \\
\hline Weighted Mean & $\begin{array}{l}\mathbf{4 . 0 4} \\
\text { bilingualism is high. }\end{array}$ & level of interest \\
\hline $\begin{array}{l}\text { Overall Interpretation } \\
\text { in }\end{array}$ \\
\hline
\end{tabular}

Legend:
$4.21-5.00$
Strongly Agree
Very High Level 
$3.41-4.20$
$2.61-3.40$
$1.81-2.60$
$1.00-1.80$

Agree

Moderately Agree

Disagree

Strongly Disagree
High Level

Fairly High Level

Low Level

Very Low Level

Guests" "moderately agree" that they must learn English as quickly as possible,

mean $=3.71$ and $\mathrm{SD}=1.06$, and prefer English over MT as as revealed by the mean on 3.33 and SD of 0.99.

As shown by the mean of 4.38 and 4.37 and SD of 0.98 and 1.01 respectively, guests' "agree" that the use of both languages helps understand the lessons better and it is interesting when guests' used both languages in a conversation.

Moreover, the obtained overall mean of 4.04 and SD of 0.63 indicates that level of Asian interest in bilingualism is high.

In researcher's perception, the guests' thinks that literacy in both MT and English is vital in writing and reading, learning, development of mental skills and career related advantages. This believed to arouse that level of interest of student in bilingualism, using both languages in school.

According to Place (2011), interest insisted on the relationship (generally positive) between individuals and the object of interest.

Table 2 shows the mean, standard deviation and remarks regarding the status of dual language exposure.

As shown in the table the tour guides "often" ask the guests to use English during conversation as revealed by the mean of 4.18 and standard deviation of 0.75 . The guests also "often "answer their tour guides question in English during the conversation as shown by the mean of 3.46 and SD of 0.78 . The guests "often use English during discussion as supported by the mean of 3.98, 4.16 and 3.98 and SD of 1.000 .85 and 0.77 respectively.

Table 2. Level of Second Language Exposure

\begin{tabular}{|l|l|l|l|}
\hline Rate & Mean & SD & Remarks \\
\hline $\begin{array}{l}\text { 1. The tour guide ask me to use English during } \\
\text { conversation. }\end{array}$ & 4.18 & 0.75 & Often \\
\hline $\begin{array}{l}\text { 2. I answer the tour guides question in English } \\
\text { during conversation. }\end{array}$ & 3.46 & 0.78 & Often \\
\hline 3. I use English during tour activities & 3.98 & 1.00 & Often \\
\hline 4. I use English when chatting. & 4.16 & 0.85 & Often \\
\hline 5. I use English during discussion. & 3.98 & 0.77 & Often \\
\hline Weighted Mean & 3.95 & 0.55 & Often \\
\hline Interpretation & $\begin{array}{l}\text { The guests' level of Second Language Exposure is } \\
\text { Exposed. }\end{array}$ \\
\hline
\end{tabular}

Legend
$4.21-5.00$
Always
High Exposed
$3.41-4.20$
Often
Exposed 


$\begin{array}{lll}2.61-3.40 & \text { Sometimes } & \text { Moderately Exposed } \\ 1.81-2.60 & \text { Seldom } & \text { Less Exposed } \\ 1.00-1.80 & \text { Never } & \text { Not Exposed }\end{array}$

Moreover, the guests are exposed to the English as shown by the weight mean of 3.95 and SD 0.55

According to Bromley (2005), language exposure help students develop vocabulary in language than grammar.

Table 3 shows the frequency, percentage and remarks regarding the guests' oral English Language proficiency in terms of vocabulary as to diction.

Table 3. Level of Oral English Language Proficiency in terms of Vocabulary as to Diction

\begin{tabular}{|l|l|l|l|}
\hline Rate & Frequency & Percentage & Remarks \\
\hline 5 & 25 & 20.83 & Excellent \\
\hline 4 & 78 & 65.00 & Good \\
\hline 3 & 16 & 13.33 & Adequate \\
\hline 2 & 1 & 0.83 & Weak \\
\hline 1 & 0 & 0.00 & Poor \\
\hline Total & 120 & 100.00 & \\
\hline Mean $=\mathbf{4 . 0 6}$ & \multicolumn{2}{l|}{} \\
\hline Standard deviation $=\mathbf{0 . 6 1}$ & $\begin{array}{l}\text { The oral English language proficiency of guests in } \\
\text { terms of vocabulary as to diction is good. }\end{array}$ \\
\hline Interpretation
\end{tabular}

Legend

$\begin{array}{ll}4.21-5.00 & \text { Excellent } \\ 3.41-4.20 & \text { Good } \\ 2.61-3.40 & \text { Adequate } \\ 1.81-2.60 & \text { Weak } \\ 1.00-1.80 & \text { Poor }\end{array}$

This table presents that twenty-five (25) out of one hundred twenty (120) guests or $20.83 \%$ were rated 5 "excellent" as the level of oral English language proficiency in terms of vocabulary as to diction. Sixty-five (65) percent of the respondents or 75 guests were graded 4 or "good" sixteen student or $13.3 \%$ got a grade of 3 or "Adequate" and only one of the respondents or $0.83 \%$ was graded "weak"

In general, vocabulary in terms of diction got a mean score of 4.06 and standard deviation of 0.61 which connotes that student have a "good" use of correct and persuasive, words and expressions.

English vocabulary is particularly extensive; thus, vocabulary instruction is a major for both teacher and learners. Student should encounter and re-encounter words to develop vocabulary it is possible by speaking and purposeful, and intelligent reading to enlarge thin vocabulary.

Table 4 shows the frequency, percentage and remark regarding the students' oral English language proficiency in terms of grammar as to syntax. 
This table present that only six (6) out of one hundred twenty (120) guests or $5 \%$ were rated 5 or "excellent" as the level of oral English language proficiency in terms of grammar as to syntax. Sixty-nine (69) student or $57.57 \%$ were graded 4 or "good" Forty-Four (44) or $36.67 \%$ got a grade of 3 or "adequate"

In general, grammar in terms of syntax, got a mean score of 3.67 and standard deviation of 0.58 which connotes that student have some minor errors in the structure of their responses which do not interfere with comprehension of their answer.

Table 4. Level of Oral English Language Proficiency in terms of Grammar to Syntax

\begin{tabular}{|l|l|l|l|}
\hline Rate & Frequency & Percentage & Remarks \\
\hline 5 & 6 & 5.00 & Excellent \\
\hline 4 & 69 & 57.50 & Good \\
\hline 3 & 44 & 36.67 & Adequate \\
\hline 2 & 1 & 0.83 & Weak \\
\hline 1 & 0 & 0.00 & Poor \\
\hline Total & 120 & 100.00 & \\
\hline Mean = 3.67 & \multicolumn{3}{|l|}{} \\
\hline Standard deviation $=\mathbf{0 . 5 8}$ & $\begin{array}{l}\text { The oral English language proficiency of guests in } \\
\text { terms of grammar as to syntax is good. }\end{array}$ \\
\hline \multicolumn{4}{|l}{} \\
\hline
\end{tabular}

Legend

$\begin{array}{ll}4.21-5.00 & \text { Excellent } \\ 3.41-4.20 & \text { Good } \\ 2.61-3.40 & \text { Adequate } \\ 1.81-2.60 & \text { Weak } \\ 1.00-1.80 & \text { Poor }\end{array}$

Table 5 shows the frequency, percentage and remark regarding the guests' oral English Language proficiency in terms of grammar as to subject and verb agreement.

This table shows that only $11.67 \%$ or 14 out of 120 guests got 5 or "excellent" as the level of oral English language proficiency in terms of grammar as to subject and verb agreement. Seventy-one guests' or $59.17 \%$ got a remark 4 or "good"; Thirty-five (35) or $29.17 \%$ got a grade of 3 . Agreement

Table 5. Level of Oral English Language Proficiency in terms of Grammar as to Subject and Verb

\begin{tabular}{|l|l|l|l|}
\hline Rate & Frequency & Percentage & Remarks \\
\hline 5 & 14 & 11.67 & Excellent \\
\hline 4 & 71 & 59.17 & Good \\
\hline 3 & 35 & 29.17 & Adequate \\
\hline
\end{tabular}




\begin{tabular}{|l|l|l|l|}
\hline 2 & 0 & 0.00 & Weak \\
\hline 1 & 0 & 0.00 & Poor \\
\hline Total & 120 & 100.00 & \\
\hline Mean - 3.83 & \\
\hline Standard Deviation - 0.62 & $\begin{array}{l}\text { The oral English language proficiency of guests in } \\
\text { terms of grammar as to subject and verb } \\
\text { agreement is good. }\end{array}$ \\
\hline Interpretation & \begin{tabular}{l} 
agod \\
\hline
\end{tabular}
\end{tabular}

Legend:

$\begin{array}{cc}4.21-5.00 & \text { Excellent } \\ 3.41-4.20 & \text { Good } \\ 2.61-3.40 & \text { Adequate } \\ 1.81-2.60 & \text { Weak } \\ 1.00-1.80 & \text { Poor }\end{array}$

In general, grammar in terms of Subject and verb agreement got a mean score of 3.83 and standard deviation of 0.62 which connotes that guests have minor errors subject - verb agreement which do not interfere with comprehension.

Table 6 shows the mean and remarks regarding the guests' oral English Language proficiency in terms of grammar.

Table 6. Level of Oral English Language Proficiency in terms of Grammar.

\begin{tabular}{|c|c|c|c|}
\hline Grammar & Mean & SD & Remarks \\
\hline Syntax & 3.67 & 0.58 & Good \\
\hline $\begin{array}{l}\text { Subject and Verb } \\
\text { Agreement }\end{array}$ & 3.83 & 0.62 & Good \\
\hline \multicolumn{4}{|l|}{ OverallMean - 3.75} \\
\hline \multicolumn{4}{|l|}{ Standard Deviation - 0.60} \\
\hline Interpretation & & \multicolumn{2}{|c|}{$\begin{array}{l}\text { The oral English language proficiency of guests } \\
\text { in terms of grammar is good. }\end{array}$} \\
\hline
\end{tabular}

Legend:

$\begin{array}{cc}4.21-5.00 & \text { Excellent } \\ 3.41-4.20 & \text { Good } \\ 2.61-3.40 & \text { Adequate } \\ 1.81-2.60 & \text { Weak } \\ 1.00-1.80 & \text { Poor }\end{array}$

This table presents that syntax got a mean of 3.67 with standard deviation of 0.58 as subject and verb agreement got a mean of 3.83 and SD of 0.62 which both got the remarks of "good". 
As revealed by the overall mean of 3.75 and standard deviation of 0.60 , the oral English Language proficiency in terms of grammar is "good".

Grammar is an important element of any language. People tend to be more particular in grammar in spoken language causing most students to be afraid to express themselves in English.

According to Butterfield (2008), grammar is a set of structural rules that governs the composition of clauses, phrases, and words in any given natural language. The term refers also to the study of such rules, and this field includes morphology, syntax and phonology, often complemented by phonetics, semantic and pragmatics. Linguists do not normally use the term to refer to orthographic rules, although usage of books and style guides that teach correct grammar may also refer to spelling and punctuation.

Table 7 shows the frequency, percentage and remarks regarding the students' oral English language proficiency in terms of fluency as to pronunciation.

This table shows that only $30 \%$ or 35 out of 120 guests' got 5 or "excellent" as the level of oral English language proficiency in terms of fluency as to pronunciation. Fifty-six (56) students or $46.67 \%$ got a remark of 4 of "good"; Twenty-eight (28) or $23.33 \%$ got a grade of 3 or (adequate).

In general, fluency in terms of pronunciation got a mean score of 4.07 and standard deviation of 0.73 which connotes that students speak with some minor errors in pronunciation, some effort in articulation in target language with some hesitation but communication is not affected.

In the researcher's perception, guests' should converse fluency in English with the students during classroom discussion since students tend to mimic the teacher's pronunciation of words. The more they are exposed to a certain language and pronunciation, the faster they acquire such language.

Table 7. Level of Oral English Language Proficiency in terms of Fluency as to Pronunciation

\begin{tabular}{|l|l|l|l|}
\hline Rate & Frequency & Percentage & Remarks \\
\hline 5 & 36 & 30.00 & Excellent \\
\hline 4 & 56 & 46.67 & Good \\
\hline 3 & 28 & 23.33 & Adequate \\
\hline 2 & 0 & 0.00 & Weak \\
\hline 1 & 0 & 0.00 & Poor \\
\hline Total & 120 & 100.00 & \\
\hline Mean -4.07 & & \\
\hline Standard Deviation $-\mathbf{0 . 7 3}$ & $\begin{array}{l}\text { The oral English language proficiency of guests } \\
\text { in terms of fluency is good. }\end{array}$ \\
\hline
\end{tabular}

Legend:

4.21-5.00 Excellent




$\begin{array}{lc}3.41-4.20 & \text { Good } \\ 2.61-3.40 & \text { Adequate } \\ 1.81-2.60 & \text { Weak } \\ 1.00-1.80 & \text { Poor }\end{array}$

According to Senel (2006), age plays a vital role in learning or improving pronunciation abilities. As can be seen, if guests' can pronounce a second language with native like accent, they must have probably started to learn it during their childhood since these guests' started their second language learning process in the target language speaking people environment. But again, there are too many factors contributing to language proficiency.

Table 8 shows the mean, SD and remarks regarding the oral English language proficiency in terms of vocabulary, grammar and fluency.

Table 8. Level of Oral English Language Proficiency

\begin{tabular}{|l|l|l|l|}
\hline $\begin{array}{l}\text { Oral English } \\
\text { Language } \\
\text { Proficiency }\end{array}$ & Mean & SD & Remarks \\
\hline Vocabulary & 4.06 & 0.61 & Good \\
\hline Grammar & 3.75 & 0.60 & Good \\
\hline Fluency & 4.07 & 0.73 & Good \\
\hline Overall Mean - 3.96 & $\begin{array}{l}\text { The level of guests' oral English proficiency is } \\
\text { good. }\end{array}$ \\
\hline $\begin{array}{l}\text { Standard Deviation } \mathbf{0 . 6 5} \\
\text { Interpretation }\end{array}$
\end{tabular}

Legend:

$\begin{array}{lc}4.21-5.00 & \text { Excellent } \\ 3.41-4.20 & \text { Good } \\ 2.61-3.40 & \text { Adequate } \\ 1.81-2.60 & \text { Weak } \\ 1.00-1.80 & \text { Poor }\end{array}$

This table shows that the level of oral English language proficiency in terms of vocabulary got a mean of 4.06 and SD of 0.61, grammar got a mean of 3.75 and SD of 0.60 and fluency got a mean of 4.07 and SD of 0.73 which all got a remark of "good".

As revealed by an overall mean of 3.96 and SD of 0.65 , oral English language proficiency of selected guests' is good.

Wallace (2007) recognizes the importance of English proficiency. According to him, English is very much needed in order to meet demands for highly equipped graduates globally. It was also stated that being proficient in the English language is one of the keys to become globally competitive. It has also been the 
language in education and business.

Table 9 shows interest in bilingualism and oral English language proficiency, f-test, p-value and interpretation.

Interest in bilingualism significantly affects oral English language proficiency in terms of vocabulary, grammar and fluency as shown by the computed f-test value of 7.57, p-value of 0.03; f-test value of 2.09 ; p-value of 0.02 ; f-test value of 6.99 , p-value of 0.04 ; f-test value of 7.51 , p-value of 0.04 respectively. Likewise, second language exposure, significantly affects oral English language proficiency in terms of vocabulary, grammar and fluency as shown by the computed f-test value of 8.08 , p-value of 0.01 ; f-test value of 9.08, p-value of 0.03; f-test value of 8.03, p-value of 0.01 , f-test value of 5.64, p-value of 0.01 respectively.

Table 9. Effect of Interest in Bilingualism and Second Language Exposure to Oral English Language Proficiency

\begin{tabular}{|c|c|c|c|c|}
\hline & $\begin{array}{l}\text { English } \\
\text { Proficiency }\end{array}$ & f-test & $\mathrm{p}$-value & Interpretation \\
\hline \multirow{4}{*}{$\begin{array}{l}\text { Interest in } \\
\text { Bilingualism }\end{array}$} & $\begin{array}{l}\text { Vocabulary } \\
\text { *Diction }\end{array}$ & 7.57 & 0.03 & 5 \\
\hline & Grammar *Syntax & 2.09 & 0.02 & 5 \\
\hline & $\begin{array}{l}* \text { Subject-verb } \\
\text { agreement }\end{array}$ & 6.99 & 0.04 & 5 \\
\hline & $\begin{array}{l}\text { Fluency } \\
\text { *Pronunciation }\end{array}$ & 7.51 & 0.04 & 5 \\
\hline \multirow{4}{*}{$\begin{array}{l}\text { Second } \\
\text { Language } \\
\text { Exposure }\end{array}$} & $\begin{array}{l}\text { Vocabulary } \\
\text { *Diction }\end{array}$ & 8.08 & 0.01 & 5 \\
\hline & Grammar *Syntax & 9.08 & 0.03 & 5 \\
\hline & $\begin{array}{l}\text { *Subject-verb } \\
\text { agreement }\end{array}$ & 8.03 & 0.01 & 5 \\
\hline & $\begin{array}{l}\text { Fluency } \\
\text { *Pronunciation }\end{array}$ & 5.64 & 0.01 & 5 \\
\hline
\end{tabular}

English has been an important tool in the teaching learning process. Keeping the interest and exposure to the second language provide opportunities for students to develop their oral English Proficiency. With this aim, making students use English in the classroom will help them develop their speaking skills in terms of vocabulary, grammar and fluency. This will also benefit them in communicating in English

\section{Discussion}

The level of interest in bilingualism as rated by the students is interpreted as of "high" as sustained by the overall mean of 4.04 and SD of 0.63 . 
The students were "exposed" to English inside their classroom as shown by the weighted mean of 3.95 and $\mathrm{SD}$ of 0.55 .

The over mean of 4.06, 3.75, 4.07 and 3.95 revealed that the oral English language proficiency in terms or vocabulary, grammar and fluency is good.

Interest in bilingualism had "significant effect" to oral English language proficiency in terms of vocabulary, grammar and fluency as shown by the computed f-test value of 7.57, p-value of 0.03 ; f-test value of 2.09, p-value of 0.02; f-test value of 6.99, p-value of 0.04; f-test value of 7.51, p-value of 0.04 respectively. Likewise, second language exposure had "significant effect" oral English language proficiency in terms of vocabulary, grammar and fluency as shown by the computed f-test value 8.08 , p-value of 0.01 ; f-test value of 9.08. p-value of 0.03 ; f-test value of 8.03, p-value of 0.01 ; f-test value of 5.64 , p-value of 0.01 .

\section{Conclusions}

Interest in bilingualism and second language exposure have "significant effect" on the oral English language proficiency in terms of vocabulary, grammar and fluency. The hypothesis was not supported.

In view of the findings and conclusions of study, the following recommendations are given:

1. Guests' should practice speaking in the second language to gain confidence.

2. Tourist attractions should create a harmonious and friendly setting.

3. Future researchers may make a further study regarding the improvement of oral English proficiency for tour guides ang guests.

\section{References}

Askari , C, G, Ed, D.(2010) Poetry, Reading, Writing what you see and what you feel, Japan; Kyoto Publishing Inc.

Asuncion ,Celodonio G, Ed (2012) Understanding Poetry Through Imagery. Philippines; Copyright Rex. Bookstore Inc.

Badillo, Aurora E. (2015) Issues in language consultations, Marilao Bulacan, Lor Mar Publishing.

Baker, C (2006), Foundations of bilingual education and bilingualism (4th ed.)See especially Chapter 17) Clevedon, UK: Multilingual Matters.

Barnhart J. (2014), Language Learning. Clevedon. England. State Publishing

Beck, C (2008). Situated Learning. York Fireside. New York

Bialystok R. (2010). Bilingual and Multilingual Education to Non- English Speakers, Department of Linguistics. Georgetown University Press U.S.A 
Carol, Rebecca (2006) D "Teaching Strategies for Reading Communication Arts, Listening, Speaking and Writing" Manila Rex Bookstore.

Canagarajah, W. (2005) "Modern English" Volume XLV, No. 4. India Phazaha Publishing

Charles, N., Brinton M. D .,\& Goodwin, J.M (2007) Teaching Pronunciation, A Reference for Teachers of English Speakers of Others Languages U.K Cambridge House of Publishing

York Fireside

Collins , Stephen and Coller, Alex (2011) The Seven Habits of highly Effective People New York;

Cutting C (2011). Seeing is understanding Improving coherence in students' writing (Online Available.hhtp://iteslj.org/Techniques/Lee-Writing ( February 10, 2009)

Duran, L (2014) Social Order in Society, Prentics Hall Press. U.S.A

Dutcher, Nadine, in collaboration with G. Richard Tucker, (1994). The use of first and second languages in education. A review of educational experience, Washington DC: World Bank, East Asia and the Pacific Region.

Gamboa J. (2007): "Significant Ways of Teachers" Florentino St., Quezon City, Rex Printing Company Inc. $84 \mathrm{P}$.

Hamer, J. (2010) Society and Language Acquisition and Learning. Prentice Hall Press U.S.A

Hart, K, (2006) Language Teaching, Chicago, New York City, U.S.A City Publishing House

Hirch (2011) Pshycology, Linguistics and Language Teaching, Chicago University of Chicago, U.S.A City Publishing House. Publishing

Kayne,J (2006). Diminishing Language Errors. Volume 29. Georgetown U.S.A, N.Y Trading and

Mclean (2010) Exposure and Language Teaching Chicago University of Chicago, U.S.A City Publishing House.

Miller S F. (2008). Pronunciation and the adult ESL learner. Retrieved September 8,2009, C.A.

Mills J (2008). Trippingly on the tongue: Putting serious speech/ pronunciation instruction back in TESOL aquation.

Nelson, W. (2005) Psychology, Linguistics and Language Teaching 1, Chicago University of Chicago U.S.A Lion Publishing House

Nelson. W. (2011) Psychology, Linguistics and Language Teaching 2. Chicago University of Chicago, U. S. A Lion Publishing House . 
Palmer, R. G.(2007) A perspective on Multiculturalism and bilingual Education Department of Linguistics Georgetown University Press

Penn, J. (2006) Assessment of Reading difficulties The reading Association of the Philippines Journal Volume 29

Ramsey, M. (2007) Social Dimension of Education,Lori Mar Publishing Co. Inc Metro Manila

Stahi.W. And Fairbank.R.(2006) Theories on Teaching and Learning. Chicago University of Chicago, U.S.A Lion Publishing House

Tucker Richard G. (1997) A global perspective on bilingualism and bilingual Education. Department of Linguistics. Georgetown University Press

Walace (2007) Bilingualism or not? The teacher and the learner translated by Lars Maimberg, Clevedon D.C Publishing

Wei. V (2006) Knowledge and Enjoyment of English Literature Rex Bookstore Inc. Sampaloc,Manila

Wilga(2009) Psychology, Linguistics and Language Teaching Chicago University of Chicago U.S.A Lion Publishing House

Zao J (2009) When reforms don't transform reflections on institutional reforms in the department of education. University of the Philippines HDN Discussion Paper Series No. 2 Quezon City

Palisin, B. (2015) Effects of Environment and Motivation to language Proficiency Unpublished Master's Thesis Laguna State Polytechnic University Sta. Cruz Laguna

Zamora , B (2008)" Effects of Respondents Profile \& Classroom Disiplinary Approaches to the Academic Performance of Grade V Pupils" Unpublished Master's Thesis. Laguna State Polytechnic University Sta.Cruz Laguna

Bacuyag, Jerry (2011) Male teachers an endangered species? Philippine Daily Inquirer. 06-28-2009

Nunn, Le Duc (2007) English as a Medium of Instruction in Asian Universities: The Case of Vietnam Language Education in Asia 3(2)

Place, Andrew J. and Young Peter (2011). Teacher Characters and Students' Gains 7(3) 89-211

Anna Papadopoulos These Are The 36 Countries In Asia With The Highest English Proficiency proficiency/

https://ceoworld.biz/2019/12/13/these-are-the-36-countries-in-asia-with-the-highest-english- 
Bromlet, Lalaine F. The Effects of bilingual instruction on the literacy skills of preschoolers. World
Reading
Congress
in
Budapest
(2005)
Available
@4april

2007@www.reading.org/downloads/wc_handouts/wc06_1_rtf

Butterfield, 2008 Bilingual Education, Accessed 10/28/2009@http://www.childrensmercy.org/ stats/definition/convenience.html.June 18,2014 ESLarticles.com.

Assessed

11/24/2014@http//media.ngberger.com/_ngb_k11/000000010.htm. Library teaching

Mclean (2010) Economy and its Effect@http://www.crie.org.nz/researvh_paper/H.Bathula_WP1.pdf Retrieved : 27/10/2012

Miffin Houghton, (2009), American Heritage Dictionary of the English Language, Accessed 11/28/2010@http://www.Miffinhgthtnk/lTTSEAL2/teaching/Education.cfd 